\title{
Qualidade de mudas de alface em função de substratos com e sem biofertilizante
}

\author{
Damiana Cleuma de Medeiros ${ }^{1 ; 2}$; Karla Cristiane de Sousa Freitas ${ }^{1}$; Francinaldo de Sousa Veras ${ }^{1}$; Regina \\ Sheila Barros dos Anjos'; Rafaela Duarte Borges'; José Galdino Cavalcante Neto ${ }^{1}$; Glauber Henrique de \\ Sousa Nunes ${ }^{1}$; Hailson Alves Ferreira ${ }^{1}$ \\ ${ }^{1}$ UFERSA, C. Postal 137, 59625-900 Mossoró-RN; ²Doutoranda em Agronomia, Fitotecnia; damianacm@ @otmail.com; \\ galdinoneto@hotmail.com; glauber@ufersa.edu.br
}

\section{RESUMO}

Avaliou-se a qualidade de mudas de alface em função de substratos com e sem biofertilizante (aplicado aos 6; 12 e 18 dias após germinação) em condições de casa-de-vegetação. $\mathrm{O}$ experimento foi conduzido em esquema fatorial inteiramente casualizado: 3 cultivares (Babá-de-Verão, Grand Rapids e Grandes Lagos) x 3 tipos de substratos (areia lavada, composto orgânico e substrato comercial Plantmax $^{\circledR}$ ) x 2 (com e sem biofertilizante), com quatro repetições. A avaliação foi feita aos 24 dias da germinação através de número de folhas, altura da parte aérea, comprimento da raiz, massa seca da parte aérea e massa seca da raiz. Houve efeito isolado dos fatores cultivares e substratos para número de folhas e comprimento da raiz. Houve efeito de interação cultivares x substratos para altura da parte aérea, massa seca da parte aérea e massa seca da raiz. Dentre as variáveis analisadas a cultivar Grand Rapids e o substrato composto orgânico foi a que obteve melhor resultado. Não houve influência significativa da aplicação de biofertilizante.

Palavras-chave: Lactuca sativa L., produção de mudas, fertilizante orgânico.

\begin{abstract}
Quality of lettuce seedlings depending on substrates with and without biofertilizer addition

The quality of lettuce seedlings depending on substrates and biofertilizer addition (at 6;12 and 18 days after germination), under greenhouse conditions was evaluated. The experiment was carried out in a completely randomized factorial scheme: 3 cultivars (Babáde-Verão, Grand Rapids and Great Lakes) x 3 substrates (washed sand, organic compost and commercial substrate Plantmax ${ }^{\circledR}$ ) x 2 (with and without biofertilizer addition), with four replications. The evaluation was done on 24-day old seedlings through number of leaves, shoot height, root length, shoot dry mass and root dry mass. There was an isolated effect for cultivars and substrates with regard to the number of leaves and root length. There was cultivars $\mathrm{x}$ substrates interaction effect for shoot height, shoot dry mass and root dry mass. The best result was obtained with cultivar Grands Rapids grown in organic compost. There were no significant effects of biofertilizer addition with respect to the evaluated variables.
\end{abstract}

Keywords: Lactuca sativa L., seedling production, organic fertilizer.

(Recebido para publicação em 9 de janeiro de 2007; aceito em 18 de abril de 2008)

\begin{abstract}
A alface é uma das hortaliças mais difundidas atualmente, sendo cultivada por todo o país. A sua larga adaptação às condições climáticas, a possibilidade de cultivos sucessivos no mesmo ano, o baixo custo de produção, a pouca suscetibilidade a pragas e a doenças e a comercialização segura, faz com que a alface seja a hortaliça preferida pelos pequenos produtores, o que lhe confere grande importância econômica e social, sendo significativo fator de agregação do homem do campo (Lima,
\end{abstract} 2005).

A agricultura orgânica é uma atividade baseada em práticas de reciclagem de matéria orgânica e uso de métodos pouco ou não agressivos ao meio ambiente na produção de alimentos saudáveis de melhor valor biológico para o consumo humano (Câmara, 2001). Essa atividade tem crescido, principalmente pela necessidade de preservação ambiental e também pela exigência de toda sociedade por alimentos mais saudáveis, sem contaminantes químicos danosos à saúde (Ambrosano, 1999).

O uso de produtos alternativos como os biofertilizantes vem crescendo em todo o Brasil. Na busca por insumos menos agressivos ao ambiente e que possibilitem o desenvolvimento de uma agricultura com menor dependência de produtos industrializados, vários produtos têm sido lançado no mercado (Deleito et al., 2000). Além disso, esses produtos podem ser produzidos pelo agricultor, gerando economia de insumos importados e, ainda, promover melhorias no saneamento ambiental. Os biofertilizantes são preparados a partir da digestão anaeróbica ou aeróbica de material orgânico e mineral, visando o fornecimento de nutrientes.
A composição química do biofertilizante varia conforme o método de preparo e o material que o origina. Para Bettiol et al, (1998), uma das principais características do biofertilizante é a presença de microrganismos, responsáveis pela decomposição da matéria orgânica, que se resulta na produção de gás e liberação de metabólicos, especialmente antibióticos e hormônios.

Aliado à qualidade das mudas, o produtor de hortaliças sente a necessidade de reduzir os custos de sua atividade. Para tanto, trabalhos são realizados no Brasil com objetivo de aproveitar material de grande disponibilidade regional, para compor o substrato visando a formação de mudas de hortaliças, em diminuição da participação de substratos comerciais (Silva et al., 2000).

O substrato se constitui no elemento mais complexo na produção de mu- 
das podendo ocasionar a nulidade ou irregularidade de germinação, a má formação das plantas e o aparecimento de sintomas de deficiência ou excesso de alguns nutrientes. $\mathrm{O}$ substrato deve apresentar características físicas, químicas e biológicas apropriadas para que possa permitir pleno crescimento das raízes e da parte aérea (Setubal \& Afonso Neto, 2000). O volume não deve variar muito quando este se encontrar seco ou molhado; deve reter suficiente umidade para que não se precise regar com muita frequiência; não deve ter um nível excessivo de salinidade, ser atóxico às plantas e estar livre de ervas daninhas. A produção da muda em substrato esterilizado é outra importante vantagem, pois ela é levada para o campo isenta de nematóides e outros fitopatógenos, que poderiam contaminá-la numa sementeira em canteiro (Caetano et al., 2001).

De acordo com Cavalcanti et al. (2002), a areia utilizada como substrato é a proveniente dos rios, a mesma utilizada para construção. A areia tem sido utilizada por diversos pesquisadores em ensaios com emergência e crescimento de várias espécies. Em qualquer granulometria, é um importante condicionador da estrutura do solo. Suas propriedades físicas proporcionam condicionamento, do qual vão depender a aeração e a permeabilidade do solo. É vantajoso utilizar areia, por esta ser de baixo custo, fácil disponibilidade e, principalmente permitir boa drenagem do substrato.

Câmara (2001), ao avaliar compostos orgânicos como substrato na produção de mudas de alface, afirma que o composto orgânico misto pode substituir com sucesso os substratos comerciais, sendo economicamente viável.

O presente trabalho tem como objetivo avaliar o uso de biofertilizante no desenvolvimento de mudas de alface de três cultivares conduzidas em três tipos de substratos.

\section{MATERIAL E MÉTODOS}

O experimento foi realizado em casa de vegetação (área coberta de 187,5 m² e sombreamento de $50 \%$ ) da UFERSA, município de Mossoró-RN.

$\mathrm{O}$ delineamento experimental utilizado foi de blocos casualizados comple- tos em esquema fatorial $3 \times 3 \times 2$, com quatro repetições. Os tratamentos resultaram da combinação dos fatores cultivares, substratos e biofertilizante. Para o fator cultivares foram utilizados: $\mathrm{C} 1$ Babá-de-verão; C2-Grand Rapids e C3Grandes Lagos. Para o fator substratos foram utilizados: S1-areia lavada ou testemunha; S2-composto orgânico misto e S3-substrato comercial Plantmax ${ }^{\circledR}$. Para o fator biofertilizante, foram utilizados: B0-Sem biofertilizante e B1Com biofertilizante. Cada parcela foi constituída de 32 células.

Para a fabricação do biofertilizante, os ingredientes foram adquiridos de abatedouro e do comércio local. A sua formulação, baseada em biofertilizante supermagro fermentado aerobicamente foi: Biofertilizante 1 (B1): $20 \mathrm{Kg}$ de folhas verdes (picadas); $40 \mathrm{~L}$ de água; $6 \mathrm{~L}$ de leite; $10 \mathrm{~L}$ de caldo de cana; $4 \mathrm{~kg}$ de cinzas; $2 \mathrm{~kg}$ de farinha de osso; $2 \mathrm{~kg}$ de calcário dolomítico. $1^{\circ}$ dia: colocou-se as folhas na água e acrescentou-se: $3 \mathrm{~L}$ de leite, $5 \mathrm{~L}$ de caldo de cana, $2 \mathrm{~kg}$ de cinzas e $2 \mathrm{~kg}$ de farinha de osso, homogeneizou-se bem e deixou-se fermentar. $7^{\circ}$ dia: adicionou-se $3 \mathrm{~L}$ de leite, $5 \mathrm{~L}$ de água com açúcar, $2 \mathrm{~kg}$ de cinzas, 2 kg de calcário dolomítico, homogeneizou-se e deixou-se fermentar por mais sete dias.

O material utilizado para compor os substratos (composto orgânico misto e areia lavada) foram adquiridos na instituição e submetidos a uma peneiração e a um tratamento térmico com água fervente $\left(100^{\circ} \mathrm{C}\right)$ dois dias antes da semeadura com a finalidade de esterilizá-los. As 24 bandejas de 128 células utilizadas foram limpas usando água corrente e após dois dias foram preenchidas com os diferentes substratos, semeando-as logo em seguida, permanecendo por 24 dias na casa de vegetação.

As análises das amostras dos substratos e dos fertilizantes foram feitas no Laboratório de análises de solo, água e planta da UFERSA de acordo com a metodologia de Silva et al. (1998). Os resultados foram: $\mathrm{pH}: 4,7$; 7,50; 8,20 $\mathrm{cmolc} \mathrm{dm}^{-3} ; \mathrm{Al}^{3+}: 0,20 ; 0,0$; 0,0; Ca+Mg: 22,50; 18,50; 4,00 cmolc $\mathrm{dm}^{-3} ; \mathrm{Na}^{+}: 3,54 ; 0,35 ; 0,23$ cmolc $\mathrm{dm}^{-3}$; $\mathrm{K}: 1,72 ; 3,17 ; 0,23 \mathrm{cmolc} \mathrm{dm}^{-3}$; P: 1047; 447,40; 78,41 $\mathrm{mg} \mathrm{dm}^{-3}$; C: 20,6; 36,70;
2,62 $\mathrm{g} \mathrm{kg}^{-1}$ para Plantmax ${ }^{\circledR}$, composto orgânico e areia lavada, respectivamente.

As irrigações foram realizadas manualmente, usando regadores com água de poço, duas vezes ao dia, pela manhã e à tarde. Oito dias após a semeadura foi efetuado o primeiro desbaste, deixando-se uma planta por célula.

Foram aplicadas três adubações foliares com o biofertilizante (de acordo com o tratamento). As aplicações foram aos 6; 12 e 18 dias após a germinação. Nesta operação usou-se um pequeno borrifador manual e a concentração de aplicação da solução era de 2,5\%. Por bandeja foram aplicados $300 \mathrm{~mL}$ de biofertilizante.

Retirou-se uma amostra de 20 plantas por parcela e determinou-se pela contagem do número médio de folhas desenvolvidas nas plantas, partindo-se das folhas basais até a última aberta, a contagem foi manual e direta.

A altura das plantas $(\mathrm{cm})$ foi determinada medindo-se do colo da planta até a extremidade mais alta, utilizandose uma régua graduada. A medição foi feita em todas as plantas de cada repetição dos 18 tratamentos.

O comprimento médio da raiz $(\mathrm{cm})$ foi determinado medindo-se do colo da planta até a extremidade inferior da raiz, utilizando-se uma régua graduada. Lavou-se o substrato na raiz das plântulas em água corrente da torneira. Após, as folhas foram colocadas em sacos de papel e levadas à estufa com circulação de ar forçada à temperatura de aproximadamente $65^{\circ} \mathrm{C}$. Após 72 horas foram retiradas, fazendo-se logo após as pesagens, em balança de precisão analítica, expressas em gramas. Os dados obtidos foram submetidos à Análise de Variância (teste F) e os tratamentos comparados através do teste de Tukey, ao nível de $5 \%$ de probabilidade pelo programa SISVAR, UFLA.

\section{RESULTADOS E DISCUSSÃO}

Observou-se efeito significativo para número de folhas e comprimento da raiz em função da cultivar e substratos (Tabela 1). A 'Babá-deverão'proporcionou maior número de folhas, diferindo estatisticamente das 
Tabela 1. Valores médios de número de folhas (NF) e comprimento da raiz (CR) de mudas de alface em função de cultivares e substratos (average values for number of leaves (NL) and root lenght (RL) of lettuce seedlings depending on cultivars and substrates). MossoróRN, UFERSA, 2005.

\begin{tabular}{lcc}
\hline Cultivar & \multicolumn{2}{c}{ Médias } \\
\cline { 2 - 3 } & NF & $\begin{array}{c}\text { CR } \\
\text { (cm) }\end{array}$ \\
\hline Babá-de-verão & $5,36 \mathrm{a}$ & $9,60 \mathrm{a}$ \\
Grand Rapids & $4,85 \mathrm{~b}$ & $10,00 \mathrm{a}$ \\
Grandes Lagos & $4,89 \mathrm{~b}$ & $8,40 \mathrm{~b}$ \\
Substrato & & \\
Areia lavada & $4,07 \mathrm{~b}$ & $6,30 \mathrm{c}$ \\
Composto orgânico & $6,42 \mathrm{a}$ & $9,34 \mathrm{a}$ \\
Plantmax® & $4,61 \mathrm{~b}$ & $7,97 \mathrm{~b}$ \\
\hline
\end{tabular}

Médias seguidas pelas mesmas letras, nas colunas, não diferem estatisticamente, entre si, pelo Teste de Tukey, a 5\% de probabilidade.

Tabela 2. Valores médios da interação cultivares x substratos para altura da parte aérea, massa seca da parte aérea e massa seca da raiz (average values for interaction cultivars x substrates for shoot height, shoot dry mass and root dry mass). Mossoró-RN, UFERSA, 2005.

\begin{tabular}{lccc}
\hline \multirow{2}{*}{ Substratos } & \multicolumn{3}{c}{ Altura da parte aérea (cm) } \\
\cline { 2 - 4 } & Babá-de-verão & Grand Rapids & Grandes Lagos \\
\hline Areia lavada & 1,74 a B & 1,66 a B & 1,52 a B \\
Composto orgânico & 3,37 b A & 4,11 a A & 3,44 b A \\
Plantimax® & 1,97 a B & 1,58 a B & 1,76 a B \\
\hline \multicolumn{4}{c}{ Massa seca da parte aérea (g) } \\
\cline { 2 - 4 } & Babá-de-verão & Grand Rapids & Grandes Lagos \\
\hline Areia lavada & 0,19 a A & 0,19 a B & 0,22 a A \\
Composto orgânico & 0,63 b A & 1,34 a A & 0,46 b A \\
Plantmax $®$ & 0,16 a A & 0,13 a B & 0,07 a A \\
\hline \multirow{4}{*yyy}{} & \multicolumn{4}{c}{ Massa seca da raiz (g) } \\
\cline { 2 - 4 } & Babá-de-verão & Grand Rapids & Grandes Lagos \\
\hline Areia lavada & 0,16 a B & 0,16 a B & 0,27 a A \\
Composto orgânico & 0,61 b A & 1,21 a A & 0,38 b A \\
Plantmax $®$ & 0,12 a B & 0,08 a B & 0,05 a B \\
\hline
\end{tabular}

Médias seguidas pelas mesmas letras maiúsculas nas colunas e minúsculas nas linhas, não diferem estatisticamente, entre si, pelo Teste de Tukey, a 5\% de probabilidade.

demais. Com relação ao comprimento da raiz, observou-se que as cultivares Babá-de-verão e Grand Rapids não diferiram estatisticamente entre si, entretanto foram superiores quando comparadas à cultivar Grandes Lagos. Estes resultados são concordantes em parte com os encontrados por Brito (2000) que observou que a cultivar Babá-deverão, apesar de não diferir estatisticamente de 'Monalisa' e 'Elisa', produziu maior número de folhas por planta, em relação às demais cultivares avaliadas.

O composto orgânico proporcionou maior número de folhas e maior comprimento da raiz, superando os demais substratos. Estes resultados são seme- lhantes aos de Barros Júnior (2001), que constatou s os perioridade dos orgânicos ao comercial em relação ao número de folhas e comprimento da raiz da alface. Apesar dos teores de matéria orgânica do substrato comercial Plantmax ${ }^{\circledR}$ serem superiores aos teores dos demais substratos (Tabela 1), os resultados indicam que o composto orgânico pode substituir com sucesso os substratos comerciais na produção de mudas de alface, com maior eficiência e menores custos.

Houve efeito significativo da interação cultivar e substrato para a altura da parte aérea (Tabela 2). No desdobramento, o substrato composto or- gânico proporcionou a maior altura da parte aérea para a cultivar Grand Rapids com relação aos demais substratos. Este resultado está de acordo com Lima (2005) que constatou maior comprimento da parte aérea em mudas de alface cultivadas em composto orgânico e submetidas à adubação foliar com Fertamin. Barros Júnior (2001) constatou que os compostos orgânicos resultaram em maior comprimento da parte aérea em comparação ao substrato comercial.

Houve efeito significativo da interação cultivar e substrato para a massa seca da parte aérea (Tabela 2). No desdobramento, o substrato orgânico proporcionou a maior massa seca da parte aérea para a cultivar Grand Rapids. Estes resultados diferiram dos de Souza (1998) que verificou que os teores de massa seca da parte aérea da alface não foram influenciados pelas doses de composto orgânico e pela presença de adubo mineral.

Houve efeito significativo da interação cultivar e substrato para a massa seca da raiz (Tabela 2). No desdobramento, o substrato orgânico proporcionou a maior massa seca da parte aérea para a cultivar Grand Rapids.

Não se observou interação significativa do biofertilizante com os tipos de substrato e cultivares e nem com fator isolado em relação às características avaliadas. Lima (2005) ao contrário, verificou que o fertilizante organo-mineral comercial Fertamin apresentou os melhores resultados para massa seca da parte aérea, número de folhas e massa seca da raiz em mudas de alface e, dentre os biofertilizantes, destacaram-se aqueles que tinham em sua composição calcário dolomítico e farinha de osso.

Em relação às variáveis analisadas, a cultivar Grand Rapids, cultivada no substrato composto orgânico, foi a que obteve melhor desempenho. Não houve influência do biofertilizante nas características avaliadas.

\section{REFERÊNCIAS}

AMBROSANO E. 1999. Agricultura ecológica. $2^{\circ}$ Simpósio de agricultura ecológica e $1^{\circ}$ encontro de agricultura orgânica. GUAIBA: Agropecuária, 398p. 
BARROS JÚNIOR AP. 2001. Diferentes compostos orgânicos como substrato na produção de mudas de pimentão (Capsicum annumm L.). Mossoró: ESAM. $31 \mathrm{p}$. (Monografia graduação).

BETTOIL W; TRATCH R; GALVÃO JAH. 1998. Controle de doenças de plantas com biofertilizantes. Jaguariúna, SP: EMBRAP CNPMA. 22p. (Circular técnico, 02).

BRITO, JR. 2000. Avaliação de cultivares de alface em Mossoró - RN. Mossoró: ESAM. 23p. (Monografia graduação).

CÂMARA MJT. 2001. Diferentes compostos orgânicos e Plantmax ${ }^{\circledR}$ como substrato na produção de mudas de alface. Mossoró: ESAM. 32p. (Monografia graduação).

CAVALCANTI NB; RESENDE GM; BRITO LTL. 2002. Emergência e crescimento do umbuzeiro (Spondias tuberosa Arr. Cam.) em diferentes substratos. Revista Ceres, v. XLIX, Suplemento março e abril, 2002. 69p.
DELEITO, CSR; CARMO GF; ABOUND ACS FERNANDES MA; 2000. Sucessão microbiana durante o processo de fabricação do biofertilizante Agrobio. In: FERTBIO 2000. Resumos... Santa Maria: Sociedade Brasileira de Ciências do solo e da Sociedade Brasileira de Microbiologia (CD-ROM).

LIMA BAB. 2005. Avaliação de mudas de alface submetidas à adubação foliar com biofertilizantes cultivadas em diferentes substratos. Mossoró: ESAM. 27p. (Monografia graduação).

SETÚBAL JWC; AFONSO NETO F. 2000. Efeito de substratos alternativos e tipos de bandejas na produção de mudas de pimentão. Horticultura Brasileira 18: 593-594.

SILVA FC; EIRA PA; BARRETO WO; PEREZ DV; SILVA CA. 1998. Análises químicas para avaliação da fertilidade do solo: métodos usados na EMBRAPA SOLOS. EMBRAPA/ Centro Nacional de Pesquisa de Solos.
SILVA ACR; FERNANDES HS; HOPPE M; MARAES RMD; PEREIRA RP; JACOB JÚNIOR EA. 2000. Produção de mudas de brócolis com vermicompostos em diferentes tipos de bandeja. Horticultura Brasileira 18: 514-515.

SOUZA PA. 1998. Avaliação de características químicas de alface cultivada sob efeito residual de um solo adubado com composto orgânico. Mossoró: ESAM. 26p. (Monografia graduação). 